\title{
Collagens VI and XII form complexes mediating osteoblast interactions during osteogenesis
}

\author{
Yayoi Izu $^{1} \cdot$ Yoichi Ezura $^{1} \cdot$ Manuel Koch $^{2} \cdot$ David E. Birk $^{3} \cdot$ Masaki Noda $^{1}$
}

Received: 19 January 2015 / Accepted: 10 December 2015 /Published online: 12 January 2016

(C) The Author(s) 2016. This article is published with open access at Springerlink.com

\begin{abstract}
Bone formation is precisely regulated by cell-cell communication in osteoblasts. We have previously demonstrated that genetic deletion of Col6al or Coll2al impairs osteoblast connections and/or communication in mice, resulting in bone mass reduction and bone fragility. Mutations of the genes encoding collagen VI cause Ullrich congenital muscular dystrophy (UCMD) and Bethlem myopathy $(\mathrm{BM})$, which have overlapping phenotypes involving connective tissue and muscle. Recent studies have identified COL12A1 gene mutations in patients with UCMD- and BMlike disorders harboring no COL6 mutations, indicating the shared functions of these collagens in connective tissue homeostasis. The purpose of this investigation has been to test the hypothesis that collagens VI and XII have coordinate regulatory role(s) during bone formation. We analyzed the localization of collagens VI and XII relative to primary osteoblasts during osteogenesis. Immunofluorescence analysis demonstrated that collagens VI and XII colocalized in matrix bridges
\end{abstract}

This work is supported by the JSPS KAKENHI (grant no. 15 K19988), the Nakatomi Foundation, and the NIH (grant no. AR044745).

Electronic supplementary material The online version of this article (doi:10.1007/s00441-015-2345-y) contains supplementary material, which is available to authorized users.

Yayoi Izu

izu.mph@mri.tmd.ac.jp

1 Department of Molecular Pharmacology, Medical Research Institute, Tokyo Medical and Dental University, M\&D Tower 24th, 5-45 1-Chome Yushima, Bunkyo-ku, Tokyo 113-8549, Japan

2 Institute for Dental Research and Musculoskeletal Biology, Center for Biochemistry, University of Cologne, Cologne, Germany

3 Department of Molecular Pharmacology \& Physiology, University of South Florida, Morsani College of Medicine, Tampa, Florida, USA between adjacent cells during periods when osteoblasts were establishing cell-cell connections. Quantification of cells harboring collagen bridges demonstrated that matrix bridges were composed of collagens VI and XII but not collagen I. Interestingly, matrix bridge formation was impaired in osteoblasts deficient in either Col6al or Col12al, suggesting that both collagens were indispensable for matrix bridge formation. These data demonstrate, for the first time, a functional relationship between collagens VI and XII during osteogenesis and indicate that a complex containing collagens VI and $\mathrm{XII}$ is essential for the formation of a communicating cellular network during bone formation.

Keywords Collagen VI · Collagen XII · Communicating cell network $\cdot$ Osteogenesis $\cdot$ Primary osteoblasts

\section{Introduction}

Bone formation is precisely regulated by cell-cell communication in osteoblasts at bone-forming sites. During bone formation, pre-osteoblasts migrate toward the bone-forming sites where osteoblasts establish connections with adjacent osteoblasts, thereby forming a communicating cell network. This network allows osteoblasts to form appropriate amounts of high-quality bone. However, the mechanisms regulating this communicating cell network are still not clear.

Cells are surrounded by extracellular matrix in vivo; this matrix provides the proper environment for cells and varies depending on specific cellular events. We have previously demonstrated that collagens VI and XII are localized at bone-forming sites and that genetic deletion of Colbal or Col12a1 causes impaired osteoblast arrangement, resulting in decreased bone mass and strength (Izu et al. 2011b, 2012). In addition, osteoblast cellular events, such as 
polarization, which is required for osteoblast terminal maturation, bone matrix secretion, and cell-cell connection/ communication via gap junctions, are impaired in Coll2aldeficient mice (Izu et al. 2011b). These data suggest that collagens VI and XII mediate cell communication during bone formation. However, the possible coordinated role(s) of collagens VI and XII in the regulation of osteoblast cell communication at bone-forming sites have not been defined.

Mutations in genes encoding collagen VI (i.e., COL6A1, COL6A2, and COL6A3) have been identified as causative in Ullrich congenital muscular dystrophy (UCMD) and Bethlem myopathy (BM). These diseases have overlapping phenotypes involving connective tissue and skeletal muscle. Both are early onset diseases, patients with UCMD have severe muscle weakness and distal joint hyperlaxity with proximal joint contractures, whereas in BM there is a relatively mild proximal weakness and distal joint contractures. However, not all patients with a clinical diagnosis of UCMD or BM have mutations in COL6 genes. Recently, COL12A1 gene mutations have been identified in patients with UCMD-like (Zou et al. 2014) and BM-like disorders (Hicks et al. 2014) without COL6 mutations. Moreover, collagen XII deficiency has also been shown to contribute to UCMD- and BM-like phenotypes, as demonstrated by genetic deletion of Col12al in mice, which results in muscular dystrophy, decreased grip strength (Zou et al. 2014), and connective tissue defects, such as kyphosis and decreased bone mass (Izu et al. 2011b). This supports the hypothesis that there is a mechanism(s) involving coordinated collagen VI and XII interactions in muscle and connective tissue development.

Collagen VI is a non-fibrillar collagen, forms characteristic microfibrillar networks, and is ubiquitously localized in connective tissues, including bone. The assembly of collagen VI is a multistep process; a short triple helical monomer consisting of $\alpha 1(\mathrm{VI}), \alpha 2(\mathrm{VI})$, and $\alpha 3(\mathrm{VI})$ is formed and subsequently assembles into disulfide bonded antiparallel dimers. The dimers further assemble into tetramers (Allamand et al. 2011; Baldock et al. 2003; Ball et al. 2003; Engel et al. 1985; Engvall et al. 1986; Mienaltowski and Birk. 2014). Collagen VI is secreted as a tetramer, which forms microfibril networks in the extracellular milieu. Collagen XII is also a non-fibrillar collagen and is widely expressed in connective tissues, including bone, ligaments, tendons, fibrocartilage, smooth muscle, skin (Walchli et al. 1994), articular cartilage (Watt et al. 1992), and cornea (Anderson et al. 2000; Hemmavanh et al. 2013). In contrast to collagen VI, collagen XII belongs to the family of fibril-associated collagens with interrupted triple helices (FACIT; Chiquet et al. 2014; Dublet et al. 1989; Gordon et al. 1987; Oh et al. 1992) and consists of a homotrimer of $\alpha 1$ (XII) chains at the $\mathrm{C}$-terminus with three non-collagenous domains and a large globular N-terminal domain. Therefore, these collagens are structurally distinct; however, mutations in both collagen genes cause common diseases.
Collagen VI interacts with a wide variety of proteins via its globular domain, which contains numerous different binding sites (Chen et al. 2015; Doane et al. 1998; Howell and Doane. 1998). On the other hand, collagen XII interacts with collagen I via the collagenous domain (Font et al. 1996; Keene et al. 1991; Koch et al. 1995; Nishiyama et al. 1994), and a large Nterminal globular domain, $\mathrm{NC} 3$, provides a possible interaction with other molecules such as tenascin X (Veit et al. 2006), decorin, and fibromodulin (Font et al. 1996, 1998; Massoudi et al. 2012). Therefore, both collagens have the ability to mediate cell-matrix and matrix-matrix interactions, which are important features regulating cell migration, adhesion, apoptosis, and survival. Based on these shared functions, there may be a common regulatory system mediated by collagens VI and XII.

Here, we demonstrate that collagens VI and XII are spatially co-localized during osteoblast development in primary osteoblasts derived from neonatal mouse calvaria. This colocalization is restricted to matrix bridges that lie between adjacent cells and that are formed when osteoblasts make cellcell connections. Since collagen I is virtually absent from matrix bridges and collagens VI and XII are indispensible for matrix bridge formation, we propose the existence of a collagen VI/XII complex that has a novel regulatory role(s) in mediating cell-cell interactions during communicating cell network formation at bone-forming sites.

\section{Materials and methods}

\section{Cell culture}

Primary osteoblasts were obtained from calvaria of wild-type, Col6a1 $1^{-/-}$, or Col1 $2 a 1^{-/-}$neonatal mice by using sequential enzyme digestion, as previously described (Izu et al. 2011b). Primary osteoblasts were maintained in $\alpha$-minimal essential medium supplemented with $10 \%$ fetal bovine serum (FBS) and antibiotics (Life Technologies, Rockville, Md., USA) as a non-osteogenic medium. Non-osteogenic medium supplemented with phospho-ascorbic acid $(100 \mu \mathrm{g} / \mathrm{ml})$ and $\beta$ glycerophosphate $(10 \mathrm{mM})$ was used as osteogenic medium to induce osteogenesis in primary osteoblasts that were previously maintained in non-osteogenic medium.

\section{Immmunolocalization analysis}

Immunofluorescence analysis was performed in primary osteoblasts as previously described (Izu et al. 2011a, 2011b). Briefly, primary osteoblasts cultured in non-osteogenic medium were seeded on $18-\mathrm{mm}$ cover slips at $2 \times 10^{4}$ cells/well in a 12-well plate and further cultured in either non-osteogenic or osteogenic medium. Cells were then fixed with $4 \%$ paraformaldehyde on days 2, 4 (confluent), and 11 (7 days after 
confluence). The coverslips were blocked with $10 \%$ goat serum with or without prior permeabilization with $0.3 \%$ Triton X-100. Samples were then incubated with rabbit polyclonal anti-collagen VI (1:500; Cosmo Bio, Tokyo, Japan), rabbit polyclonal anti-collagen XII (1:250; Izu et al. 2011b), guinea pig polyclonal anti-collagen XII (1:250; Izu et al. 2011b), and/or rabbit polyclonal anti-collagen I (1:500, Life
Technologies) at $4{ }^{\circ} \mathrm{C}$ overnight. Secondary antibodies (goat anti-rabbit IgG Alexa 488 or goat anti-guinea pig IgG Alexa 546) were used at a 1:500 dilution. As a negative control, cells were incubated with secondary antibodies only. In addition, cells were labeled with vibrant DiI (1,1'-dioctadecyl 3,3,3',3'tetramethylindocarbocyanine perchlorate; 1:200; Thermo Fisher Scientific, Mass., USA), stained with Alexa-488-
Fig. 1 Collagen VI localization in primary osteoblasts cultured in non-osteogenic medium.

Immunofluorescence analysis of collagen VI was performed in primary osteoblasts under nonosteogenic conditions. The cells were harvested on days 2 (a-c), 4 (d-f), and 11 (g-i) and immunostained for collagen VI (red) with permeabilization by Triton X-100. Phalloidin (green) and DAPI (blue) were used to detect cell shape and nuclei, respectively. As shown in the merged images, collagen VI immunoreactivity was observed intra- and extracellularly. Extracellular collagen VI was localized between adjacent osteoblasts (arrows) on day 2 (a, b). This extracellular localization was gradually increased on days 4 (d, e) and 11 (g, h). Bars $50 \mu \mathrm{m}$. On day 4, osteoblasts were stained for collagen VI (green) without permeabilization and then captured by confocal microscopy (j-n). DiI (red) and DAPI (blue) were used to detect cell shape and nuclei, respectively ( $2 a b$ secondary antibody only as a control (n)). As shown in the high magnification image in the inset from the merged image ( $\left.\mathbf{j}^{\prime}\right)$, extracellular collagen VI connected cell bodies without the presence of protrusions. Bars $25 \mu \mathrm{m}$

\section{Intra-and extracellular collagen $\mathrm{VI}$ in non-osteogenic medium}

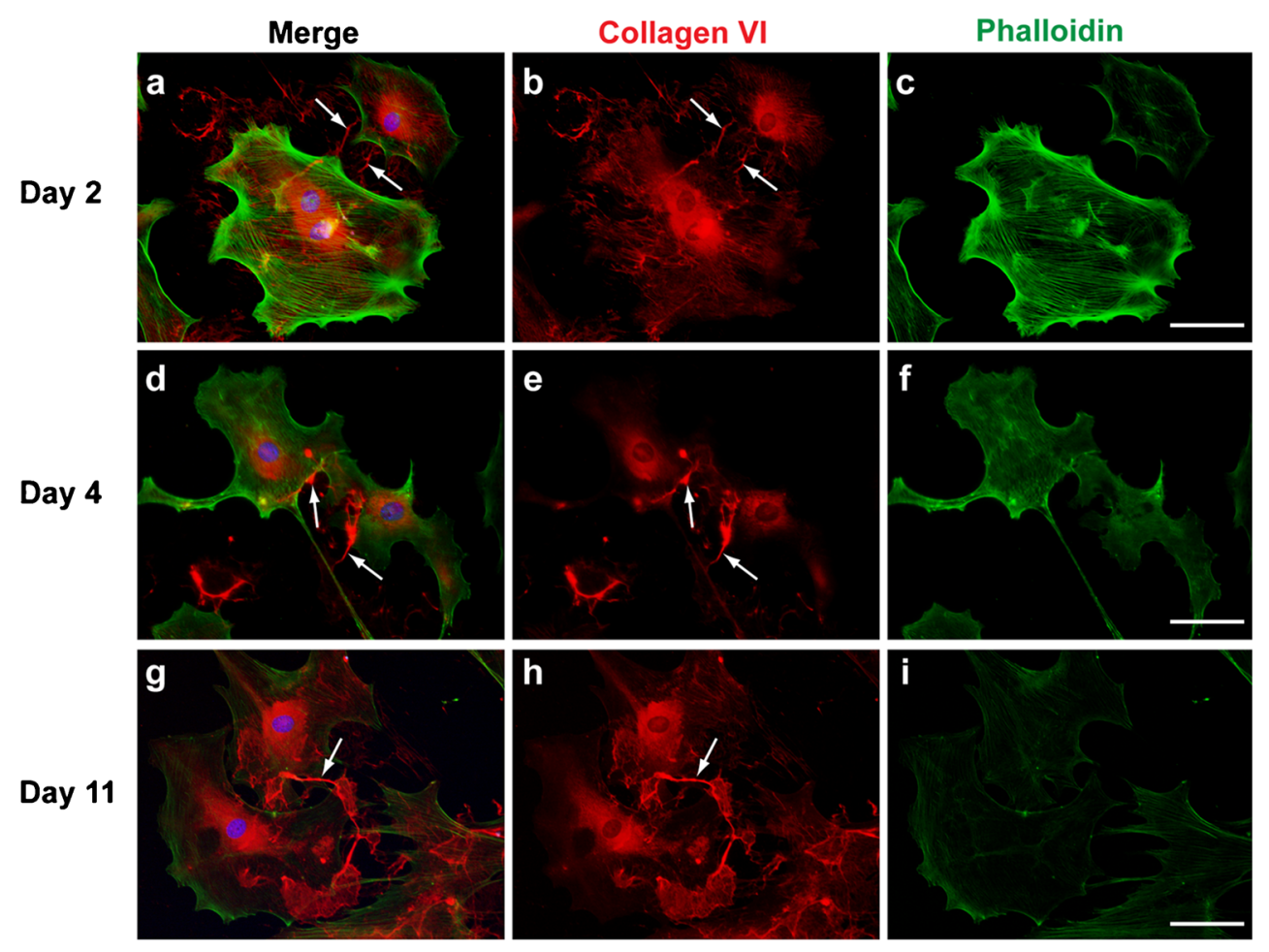

Extracellular collagen $\mathrm{VI}$ in non-osteogenic medium
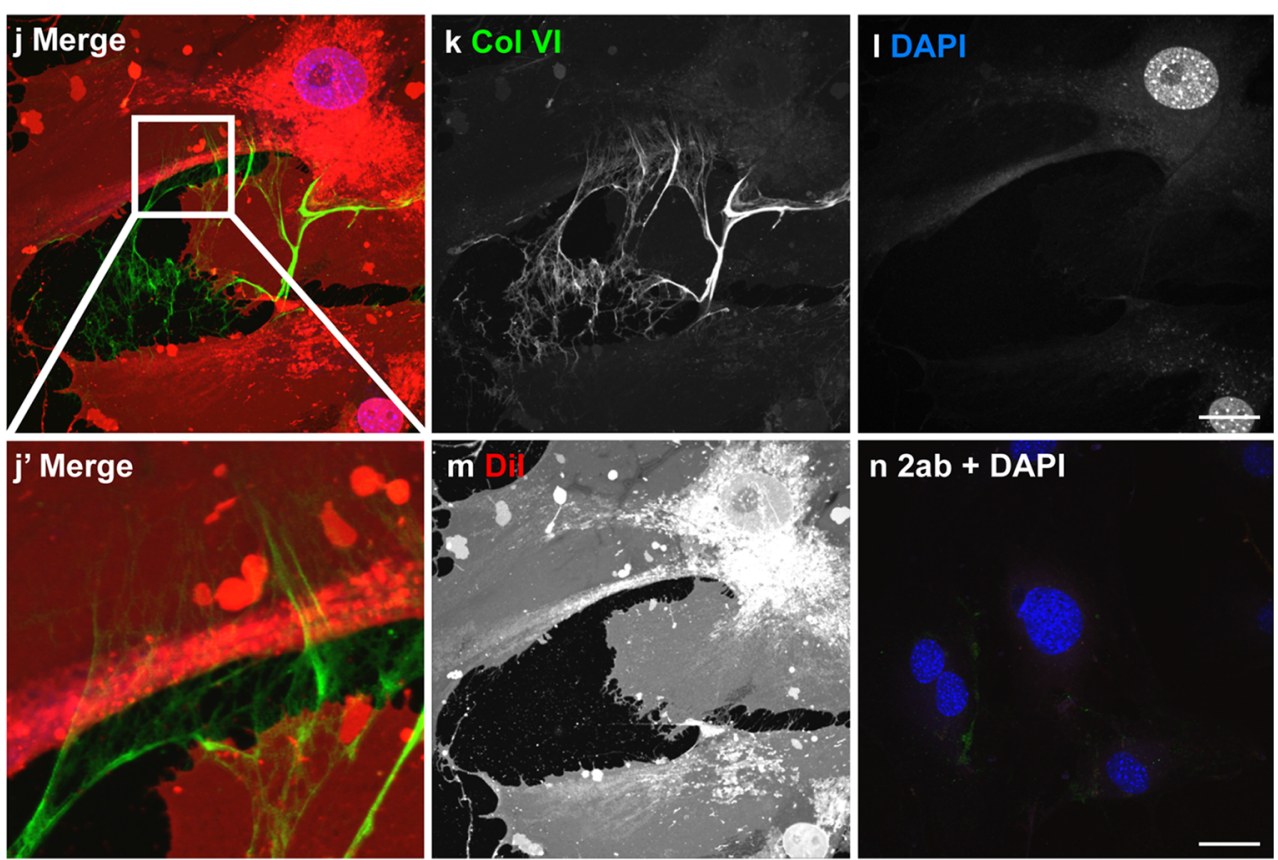
labeled phalloidin (1:200; Life Technologies), or imaged as phase contrast to visualize cell shapes. Prolong Gold DAPI (4, 6-diamidino-2-phenylindole) mounting medium (Life Technologies) was used for nuclear localization. Images were captured by using a confocal laser-scanning microscope (Fluo-View FV10i; Olympus, Tokyo, Japan) or a fluorescence microscope (Olympus BX51; Olympus).

\section{Western blot analysis}

Primary osteoblasts cultured for 2, 4, or 11 days were used for western blot analysis. Medium was changed to nonosteogenic or osteogenic medium without FBS 1 day before harvesting. Media and cells, which were lysed in lysis buffer containing $50 \mathrm{mM}$ TRIS-HCl, $1 \mathrm{M} \mathrm{NaCl}, 10 \mathrm{mM}$ EDTA, and
Fig. 2 Collagen VI localization in matrix bridges connecting adjacent cells in osteogenic medium. Immunofluorescence analysis of collagen VI was performed in primary osteoblasts in osteogenic medium. The cells were harvested on days 2 (a-c), 4 (d-f), and 11 (g-i) and immunostained for collagen VI (red) with permeabilization by Triton X-100. Phalloidin (green) and DAPI (blue) were used to detect cell shape and nuclei, respectively. As shown in the merged image, collagen VI immunoreactivity was observed intra- and extracellularly. Extracellular collagen VI was localized between adjacent osteoblasts (arrows) on day 2 (a, b). This extracellular localization was gradually increased on days 4 $(\mathbf{d}, \mathbf{e})$ and $11(\mathbf{g}, \mathbf{h})$. Osteogenic medium increased collagen VI expression when compared to non-osteogenic medium. Bars $50 \mu \mathrm{m}$. On day 4, osteoblasts were stained for collagen XII (green) without permeabilization and then captured by confocal microscopy (j-n). The merged image demonstrates that extracellular collagen VI is localized between adjacent cells ( $2 a b$ secondary antibody only as a control (n)). The high magnification image in the inset from the merged image reveals that extracellular collagen VI connects cell bodies without the presence of protrusions (j'). Bars $25 \mu \mathrm{m}$

\section{Intra-and extracellular collagen $\mathrm{VI}$ in osteogenic medium}

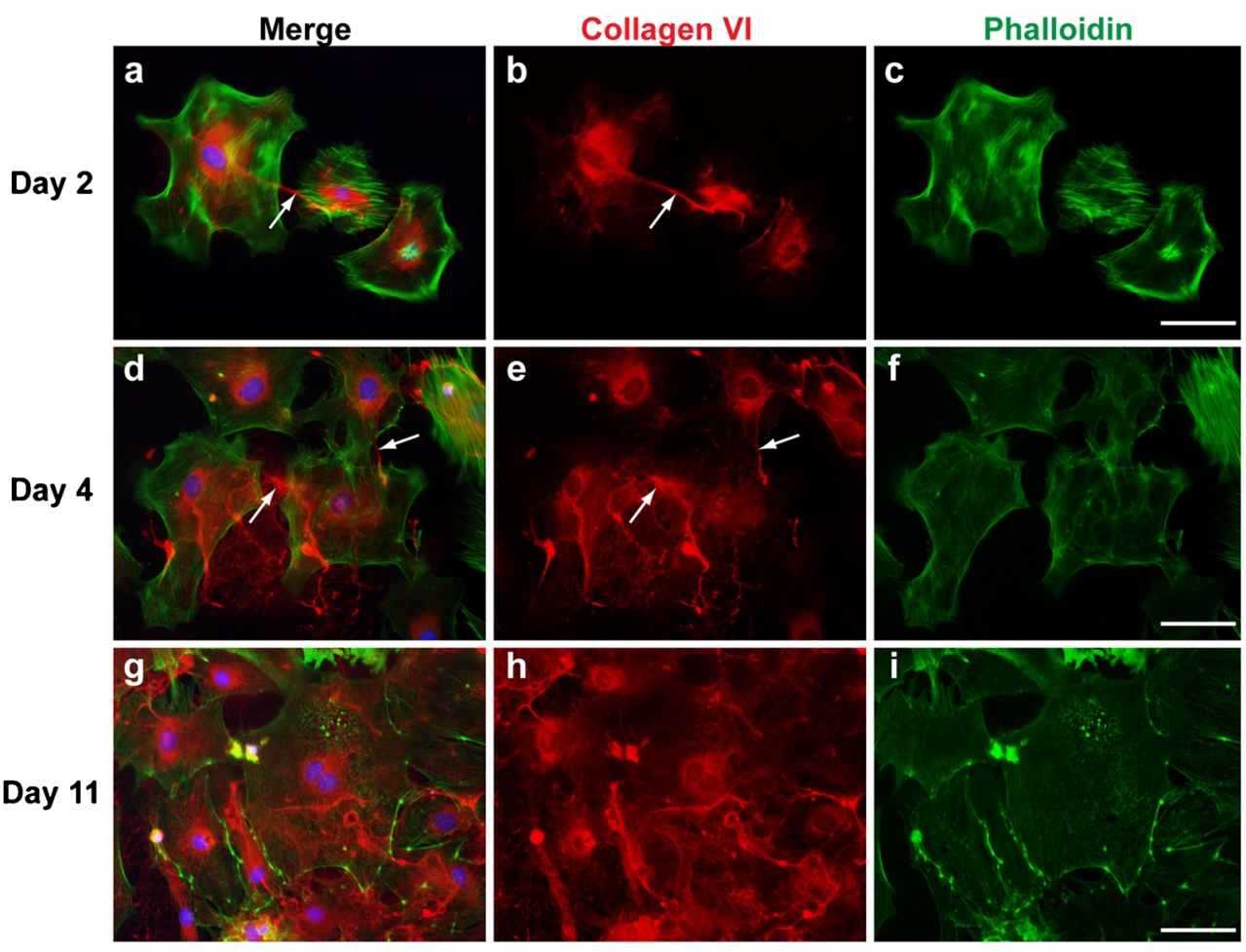

Extracellular collagen $\mathrm{VI}$ in osteogenic medium
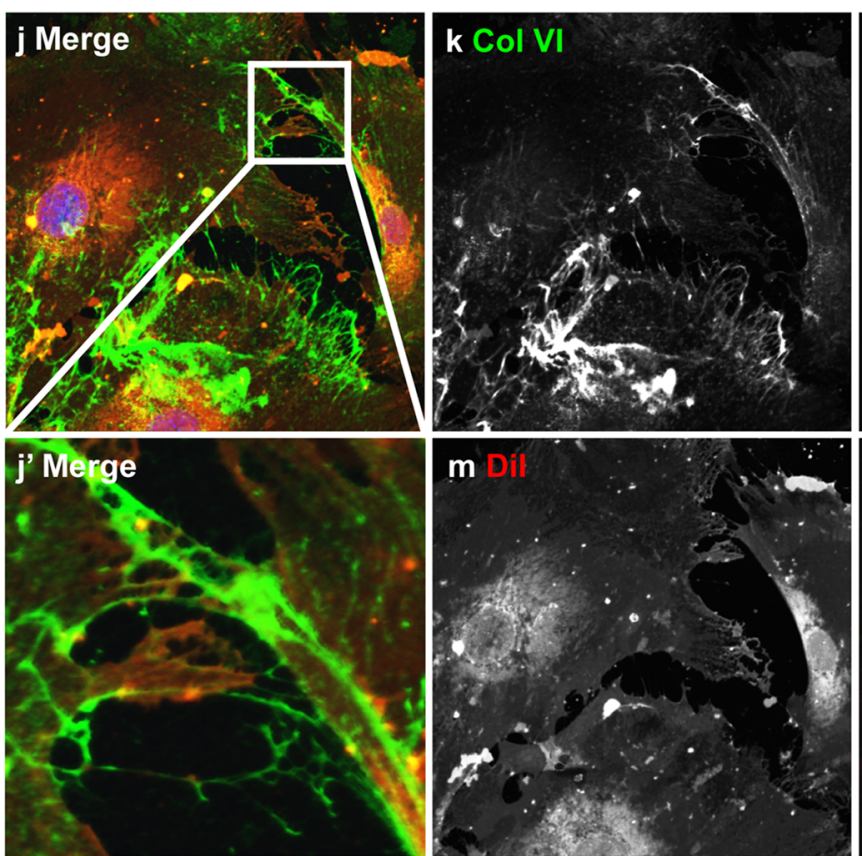
$0.1 \%$ SDS, were used for SDS-polyacrylamide gel electrophoresis (SDS-PAGE) and western blotting. SDS-PAGE was performed with 4-15\% acrylamide gel under denaturing conditions. Western blotting was performed as previously described (Izu et al. 2009) by using rabbit polyclonal anti-collagen VI (1:1000; Novus Biologicals, Littleton, Colo., USA), rabbit polyclonal anti-collagen XII (1:1000; Izu et al. 2011b), rabbit polyclonal anti-collagen I (1:3000; Life Technologies), and mouse anti- $\beta$-actin (1:4000; Sigma, St Louis, Mo., USA) primary antibodies and anti-mouse or anti-rabbit horseradish peroxidase (HRP)-conjugated secondary antibodies (Jackson ImmunoResearch, Westgrove, Pa., USA).
Fig. 3 Collagen XII is not localized extracellularly in nonosteogenic medium.

Immunofluorescence analysis of collagen XII was performed in primary osteoblasts in nonosteogenic medium. The cells were harvested on days 2 (a-c), 4 (d-f), and 11 (g-i) and immunostained for collagen XII (red) with permeabilization. Phalloidin (green) and DAPI (blue) were used to detect cell shape and nuclei, respectively. Immunoreactivity for collagen XII was observed intracellularly but not extracellularly at all the stages. Bars $50 \mu \mathrm{m}$. On day 4, osteoblasts were stained for collagen XII (green) without permeabilization and then captured by confocal microscopy (j-n). DiI (red) and DAPI (blue) were used to detect cell shape and nuclei, respectively ( $2 a b$ secondary antibody only as a control). As shown in the merged image, no immunoreactivity was detected for collagen XII. The high magnification image in the inset from the merged image reveals no collagen XII immunoreactivity between adjacent cells connected by cell protrusions, as shown by DiI staining (j'). Bars $25 \mu \mathrm{m}$

\section{Intra-and extracellular collagen XII in non-osteogenic medium}

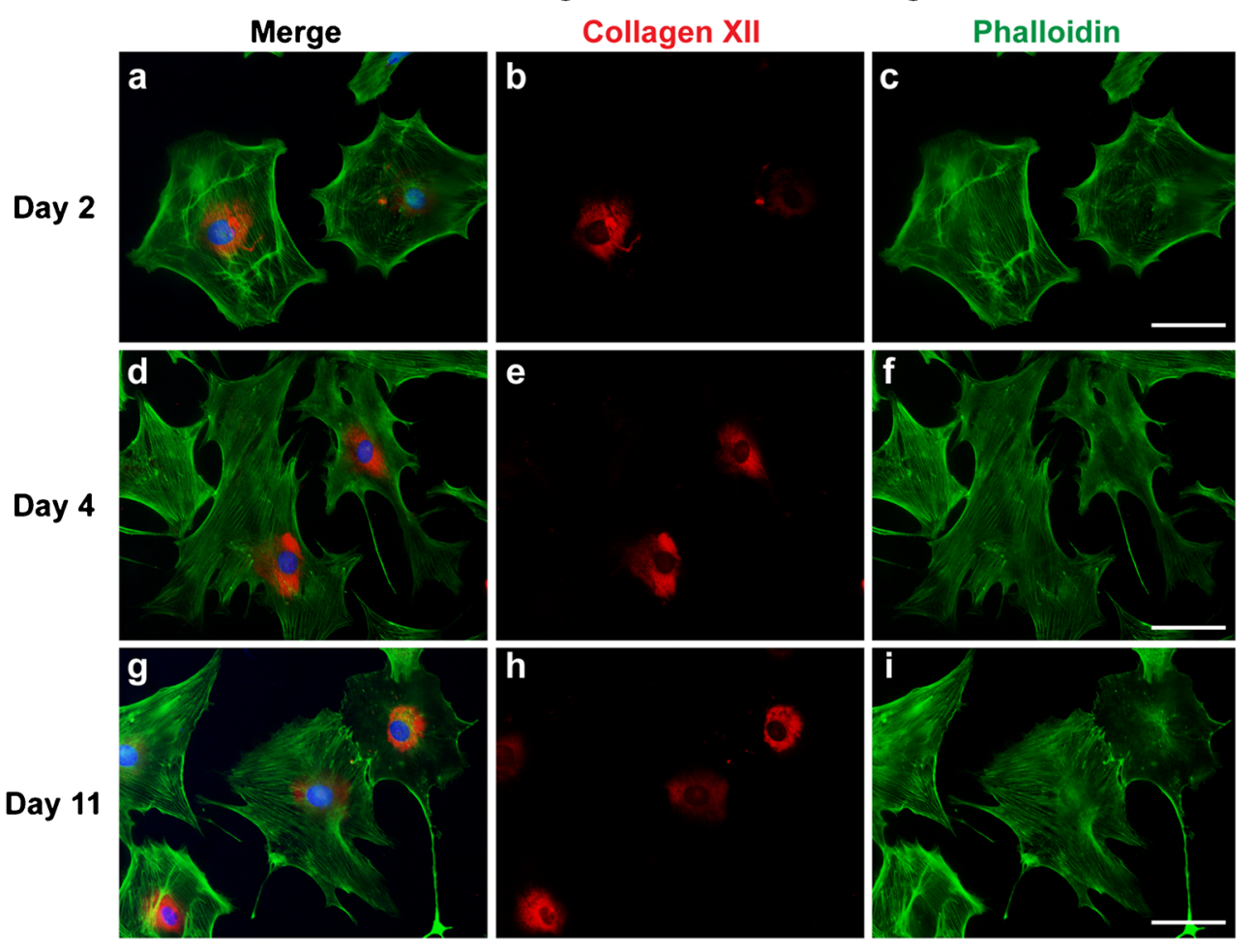

Extracellular collagen XII in non-osteogenic medium
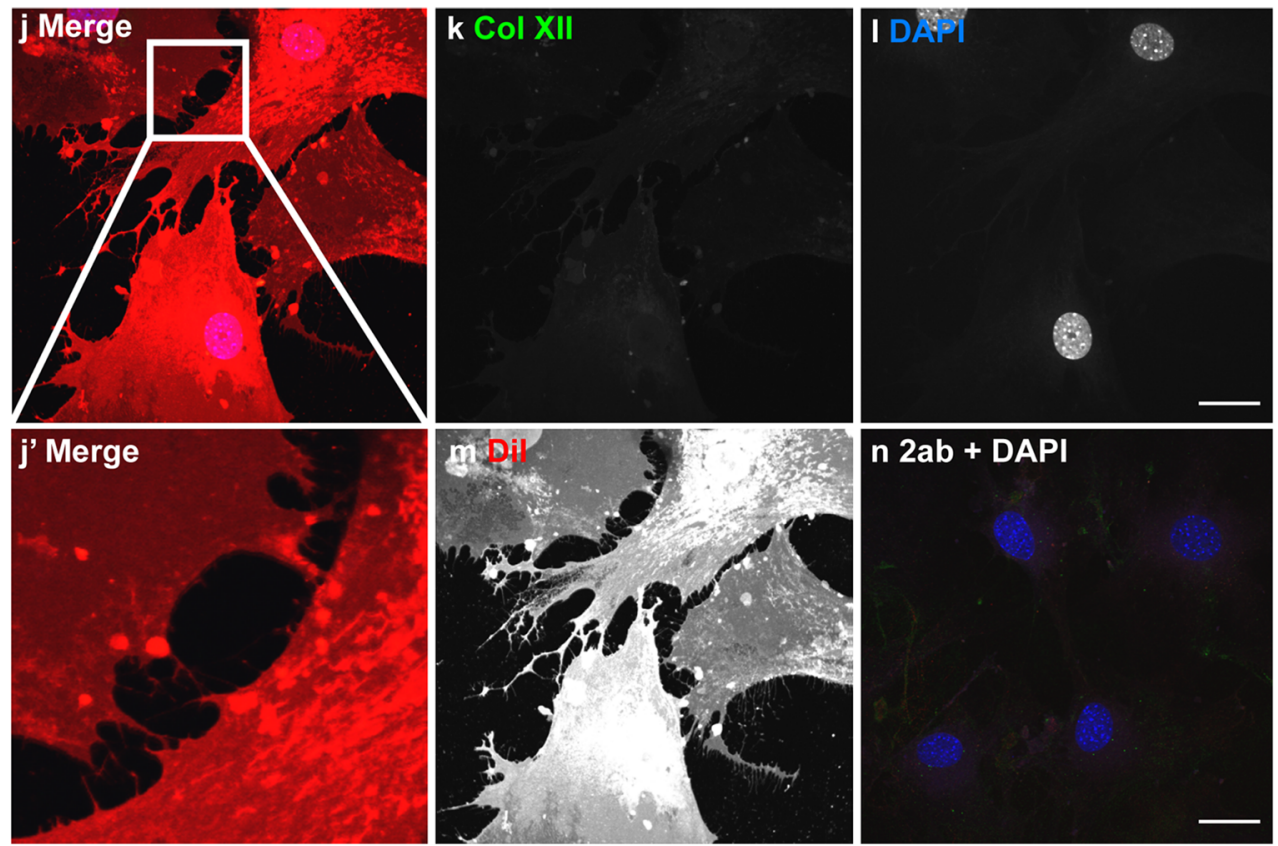


\section{Quantitative analysis of cells connected via collagen bridges}

The numbers of cells connected through collagens were analyzed. Ten digital images (magnification: $20 \times$ ) were randomly selected from cells immunostained for collagens I, VI, or XII with DiI labeling on days 2 and 4 . The total number of cells was counted by using DiI labeling to exclude cells lacking a part of the cell body. Among the total cells, cells which had collagen bridges were counted. The cell count was performed in triplicate from each immunostaining group and is given as the mean of triplicate determinants. Statistical analysis was performed by using Student's $t$-test.

\section{Results}

\section{Collagen VI links adjacent primary osteoblasts}

To analyze collagen VI localization during osteogenesis, collagen VI immunofluorescence was performed with permeabilization by using primary osteoblasts obtained from neonatal mouse calvaria. Osteoblasts were cultured in non-osteogenic medium (Fig. 1) or osteogenic medium (Fig. 2) and were harvested on days 2,4 , and 11 . In nonosteogenic medium, collagen VI was localized mainly in the cytoplasm, with some extracellular extensions directed toward adjacent cells on day 2 (Fig. 1a-c). The extracellular localization of collagen VI between adjacent osteoblasts was detected as matrix bridges, and the number of matrix bridges was increased on day 4 (Fig. 1d-f). On day 11, extracellular localization of collagen VI was increased throughout the culture thereby masking the collagen VI bridge structure (Fig. 1g-i).

To determine whether collagen VI bridges were localized in the intra- or extracellular milieu, cell shape was visualized by using DiI (a lipophilic membrane stain) and immunostaining of collagen VI without permeabilization, allowing visualization of extracellular collagen VI only. Cells from 4-day cultures in nonosteogenic medium were analyzed using confocal microscopy (Fig. 1j-n), revealing fine structures containing collagen VI. These structures formed adjacent to the cell surface and extended toward adjacent cells, resulting in the formation of matrix bridges.

Similar to our observations in non-osteogenic medium, osteogenic medium induced collagen VI matrix bridge formation and intracellular localization (Fig. 2a-i). Extracellular collagen VI was increased in osteogenic medium, compared with that in non-osteogenic medium at all stages analyzed. On days 2 and 4, when cells begin to form communicating cell networks, extracellular collagen VI was found to be expressed as matrix bridges, connecting adjacent cells (Fig. 2a-f). On day
Fig. 4 Extracellular collagen XII, but not collagen I, forms matrix bridges under osteogenic conditions. Immunofluorescence analysis of collagen XII (a-n) and collagen I (o-s) in primary osteoblasts cultured in osteogenic medium. The cells were harvested on days 2 (a-c), 4 (d-f), and 11 (g-i) and immunostained for collagen XII (red) with permeabilization. Phalloidin (green) and DAPI (blue) were used to detect cell shape and nuclei, respectively. Both intra- and extracellular immunoreactivity for collagen XII was detected. Extracellular collagen XII was localized between adjacent cells (arrows) on days $2(\mathbf{a}, \mathbf{b})$ and 4 (d, e). On day 11, collagen XII was detected as extracellular microfibril networks surrounding individual cells $(\mathbf{g}, \mathbf{h})$. Bars $50 \mu \mathrm{m}$. Confocal analysis reveals collagen XII (green) immunofluorescence without permeabilization in osteoblasts on day $4(\mathbf{j}-\mathbf{n})$. DiI (red) and DAPI (blue) were used to detect cell shape and nuclei, respectively ( $2 a b$ secondary antibody only as a control). Extracellular microfibers of collagen XII were localized between adjacent cells and connected each cell (j). As seen in the high magnification image in the inset, distinct collagen XII matrix bridges were attached to the adjacent cell $\left(\mathbf{j}^{\prime}\right)$. No cell protrusions, as shown by DiI, were observed with the matrix bridges. Bars $25 \mu \mathrm{m}$. Confocal images of collagen I (green) in primary osteoblasts cultured in osteogenic medium for 4 days, staining without permeabilization (o-s). DiI (red) and DAPI (blue) were used to detect cell shape and nuclei, respectively ( $2 a b$ secondary antibody only as a control). Extracellular collagen I was localized pericellularly (p). As shown in the high magnification image in the inset, extracellular collagen I was localized on the cell surface, and no matrix bridges were detected ( $\left.\mathbf{o}^{\prime}\right)$. Bars $25 \mu \mathrm{m}$

11, extracellular collagen VI was visualized as well-organized microfiber networks surrounding individual cells (Fig. 2g-i). The extracellular localization of collagen VI in primary osteoblasts on day 4 in osteogenic medium was analyzed by confocal microscopy without permeabilization (Fig. $2 \mathrm{j}-\mathrm{n}$ ). Extracellular collagen VI microfibers accumulated and became thicker in matrix bridges (Fig. 2j). Therefore, collagen VI may play a role in cell-cell interactions by accumulating in matrix bridges between adjacent cells beginning at early stages of osteogenesis.

\section{Extracellular collagen XII bridges adjacent cells in primary osteoblasts during osteogenesis}

To elucidate collagen XII localization during osteogenesis, collagen XII immunostaining with permeabilization was carried out in primary osteoblasts cultured under nonosteogenic (Fig. 3) or osteogenic (Fig. 4) conditions. Collagen XII localization was restricted to the cytoplasm in non-osteogenic medium (Fig. 3a-i). This was confirmed by the lack of extracellular collagen XII when the cells were immunostained without permeabilization (Fig. 3j-n). In contrast, collagen XII was detected in the intra- and extracellular milieu when cells were cultured in osteogenic medium (Fig. 4a-n). Extracellular localization of collagen XII was detected in matrix bridges on days 2 and 4 in osteogenic medium (Fig. 4a-f). By day 11, collagen XII was detected as an extracellular microfiber network (Fig. 4g-i). Detailed analysis of extracellular collagen XII localization on day 4 was performed in osteoblasts 
Intra-and extracellular collagen XII in osteogenic medium
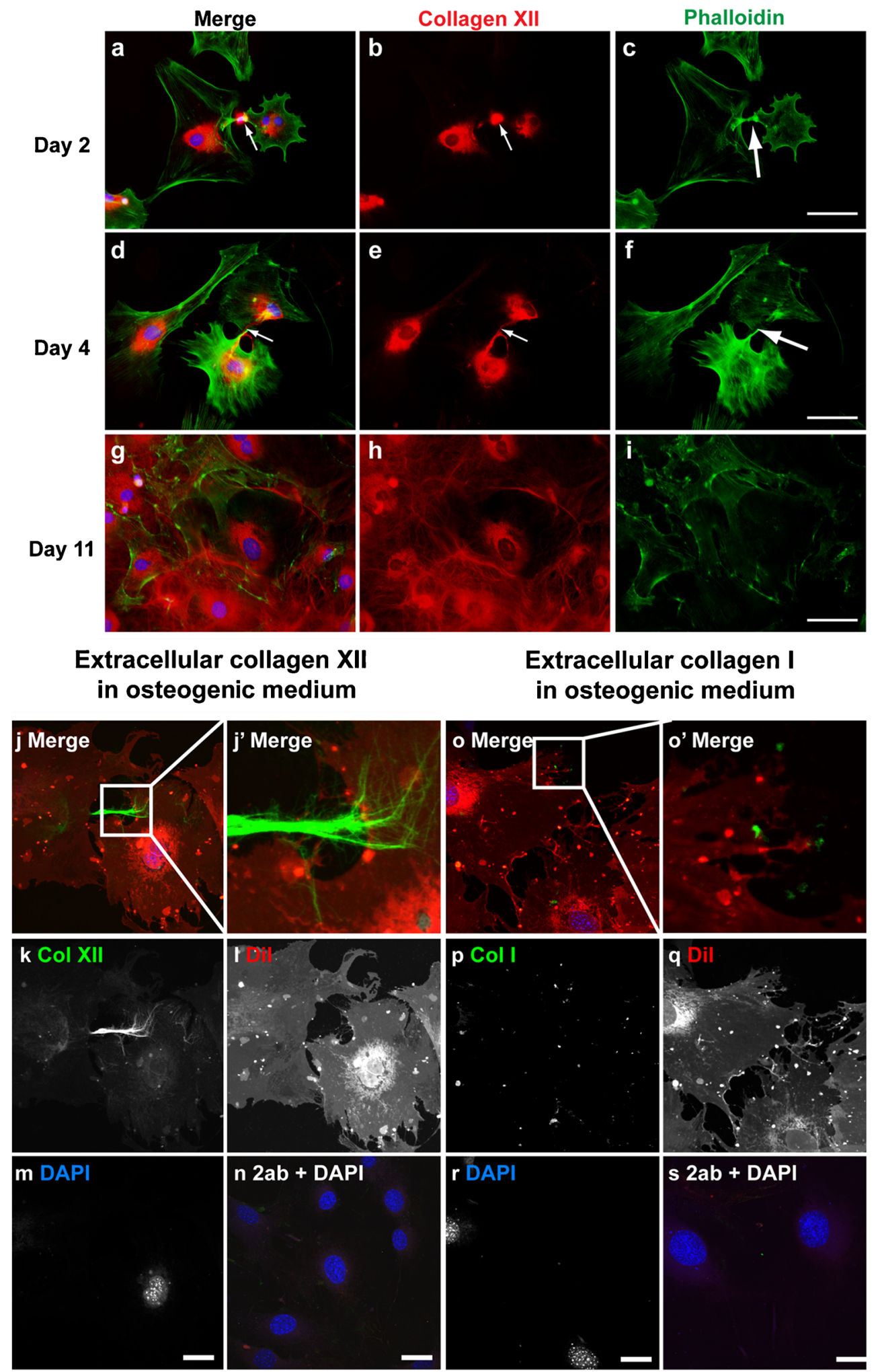

cultured under osteogenic condition without permeabilization using confocal microscopy (Fig. 4j-n). The data demonstrate that extracellular collagen XII indeed forms matrix bridges connecting adjacent osteoblasts. 
To elucidate whether collagen matrix bridges were specific for collagens VI and XII, we next investigated the localization of collagen I by confocal microscopy in primary osteoblasts cultured in osteogenic medium (Fig. 4o-s). In contrast to the observed localization of collagens VI and XII, extracellular collagen I was localized pericellularly, suggesting that collagen I does not form matrix bridges under conditions in which matrix bridges were formed by collagens VI and XII.

\section{Collagens VI and XII colocalize during formation of communicating cell networks under osteogenic conditions}

To investigate whether collagens VI and XII were colocalized in matrix bridges, double immunostaining for collagens VI and XII was performed in primary osteoblasts under nonosteogenic (Supplementary Fig. 1a) or osteogenic (Fig. 5a-g, Supplementary Fig. 1b) conditions. Under non-osteogenic conditions, only collagen VI was detected in the extracellular milieu, as expected (Supplementary Fig. 1a). In contrast, although collagen VI immunoreactivity exhibited a broader localization than that of collagen XII (Supplementary Fig. 1), both collagens were localized in matrix bridges, where they were partially colocalized on days 2 and 4 . Confocal images with phase contrast clearly demonstrated the presence of extracellular collagens VI and XII in matrix bridges, with partial colocalization observed on day 4 (Fig. 5a-g). These observations indicate that collagens VI and XII coordinately regulate the formation of communicating cell networks during osteogenesis.

\section{Collagens I and XII do not interact during matrix bridge formation}

Collagens I and XII are thought to interact during fibrillogenesis (Font et al. 1996; Keene et al. 1991; Koch et al. 1995; Nishiyama et al. 1994). Therefore, we next analyzed the localization of collagens I and XII during matrix bridge formation under non-osteogenic (Supplementary Fig. 2a) or osteogenic (Fig. 5h-n, Supplementary Fig. 2b) conditions. As expected, no extracellular localization of collagens I and XII was detected under non-osteogenic conditions (Supplementary Fig. 2a). Although collagens I and XII were colocalized close to the cell surface on days 2 and 4 in osteogenic medium, no colocalization in matrix bridges was detected. On day 11, no clear matrix bridge formation was detected because collagens I and XII were both observed in the extracellular milieu forming microfiber networks. A detailed analysis by confocal microscopy in primary osteoblasts revealed that collagens I and XII were colocalized pericellularly but not in matrix bridges in which only collagen XII immunoreactivity was observed (Fig. 5h). These data suggest that collagens I and XII do not interact during matrix bridge formation.
Fig. 5 Matrix bridge formation is specific for collagens VI and XII, but not collagen I under osteogenic conditions. Confocal images of double immunostaining for collagens VI and XII (a-g) and collagens I and XII (h-n) in primary osteoblasts cultured for 4 days under osteogenic conditions without permeabilization. DAPI (blue) and phase contrast (gray) were used to detect nuclear localization and cell shape, respectively. Osteoblasts stained with secondary antibodies and DAPI were used as a negative control $(2 a b+D A P I)$. The merged image demonstrates the localization of collagens VI (green) and XII (red) in a matrix bridge between adjacent cells (arrows in a-e). The high magnification image in the inset demonstrates partial colocalization of collagens VI and XII (a'). As shown in the merged image, colocalization of collagens I (green) and XII (red) was detected pericellularly (asterisks in h-I). The high magnification image in the inset demonstrates collagen XII localization between adjacent cells but not collagen I (h'). Bars $25 \mu \mathrm{m}$. The number of cells connected via collagens VI, XII, and I was analyzed in immunofluorescence images after cells had been cultured in osteogenic medium for 2 and 4 days (o). The mean percentages of cells which had collagen bridges were calculated based on the total number of cells observed in each image. Ten digital images were used from cells immunostained for collagens I, VI, XII, or VI and XII. Measurements were performed in triplicate. The number of cells with collagen VI or XII bridges was higher than that with collagen I bridges on day 2 . In addition, the percentage of cells which had both collagens VI and XII was significantly higher than that which had collagen I bridges. The number of cells with collagen VI, collagen XII, or both collagens VI and XII was increased, whereas that of cells with collagen I did not change on day 4. Statistical analysis revealed that the number of cells with collagen VI and/or collagen XII matrix bridges was significantly higher than that with collagen I on days $2(* P<0.06)$ and 4 $(* * P<0.005)$

To support these findings further, western blot analysis was performed in primary osteoblasts cultured in non-osteogenic or osteogenic medium (Supplementary Fig. 3). Consistent with the immunostaining data, collagens VI, XII, and I were expressed in cells cultured under both non-osteogenic and osteogenic conditions. Collagen VI expression in culture medium was similar between non-osteogenic and osteogenic conditions, whereas collagen XII expression in culture medium was only observed under osteogenic conditions, suggesting that the extracellular localization of collagen XII only occurred when cells were cultured in osteogenic medium. Similar to collagen XII, the secreted form of collagen I, which was visualized as the lower band, was only detected in osteogenic medium.

\section{Cells are bridged via collagens VI and XII, but not collagen I}

We next quantified matrix bridge formation by counting cells harboring collagen bridges (Fig. 5o). Cells were counted based on the immunofluorescence images of cells cultured under osteogenic conditions. The percentages of the cells with collagen VI bridges on days 2 and 4 were $39 \%$ and $75 \%$, respectively. Collagen XII bridges were observed in $21 \%$ of cells on day 2 and $51 \%$ of cells on day 4 . By contrast, the percentages of cells harboring collagen I on days 2 and 4 were $8 \%$ and $17 \%$, respectively. We also analyzed the percentage 
Collagen VI bridge formation

Merge
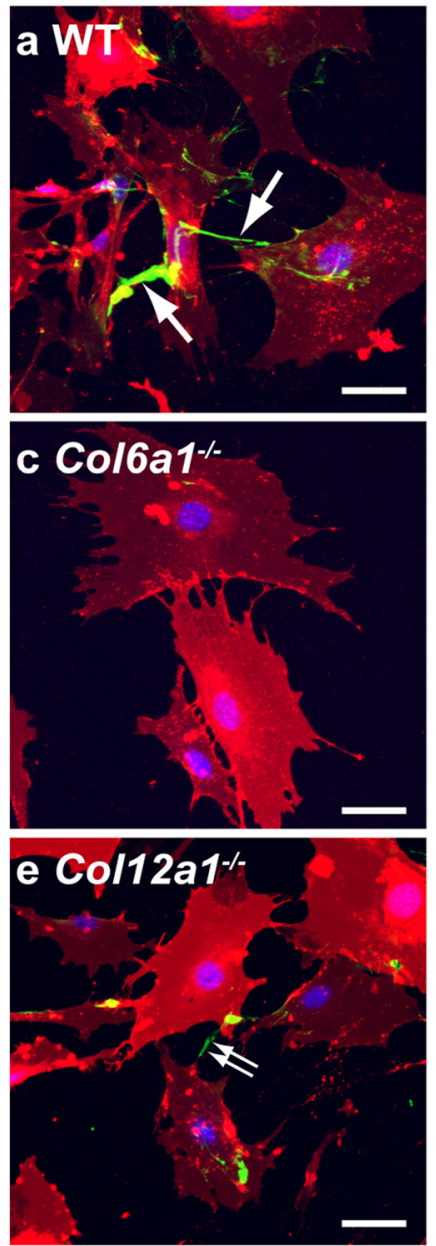

m
Col VI
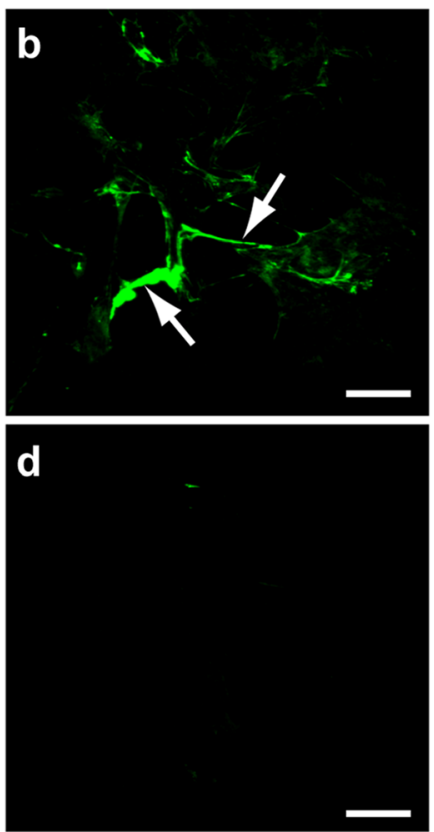

f

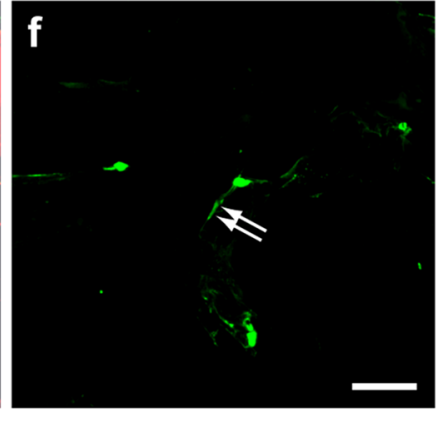

n
Collagen XII bridge formation

Merge
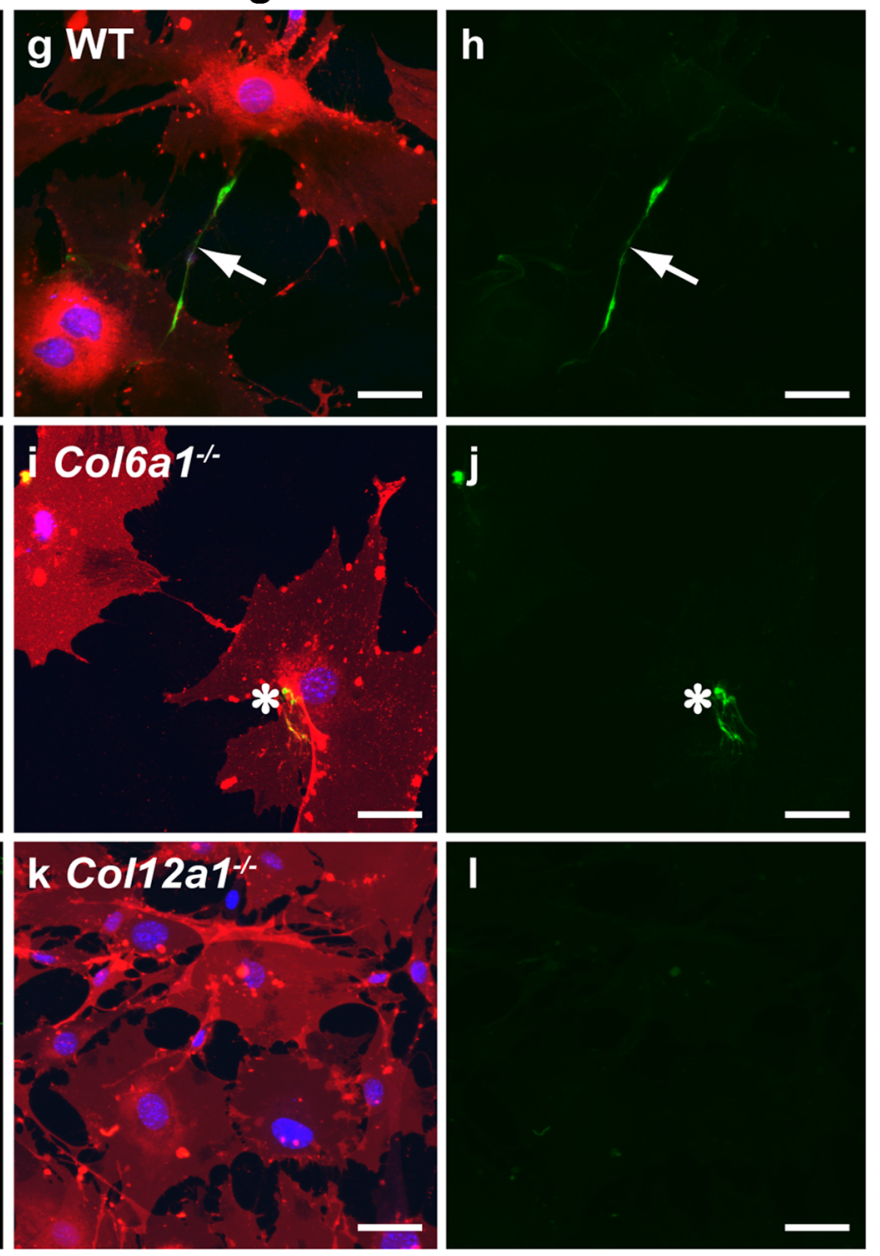

I

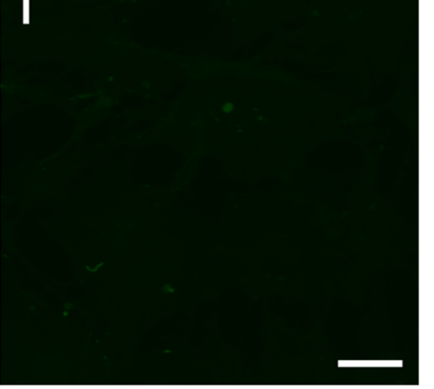

n (\%) Cells with collagen XII bridges

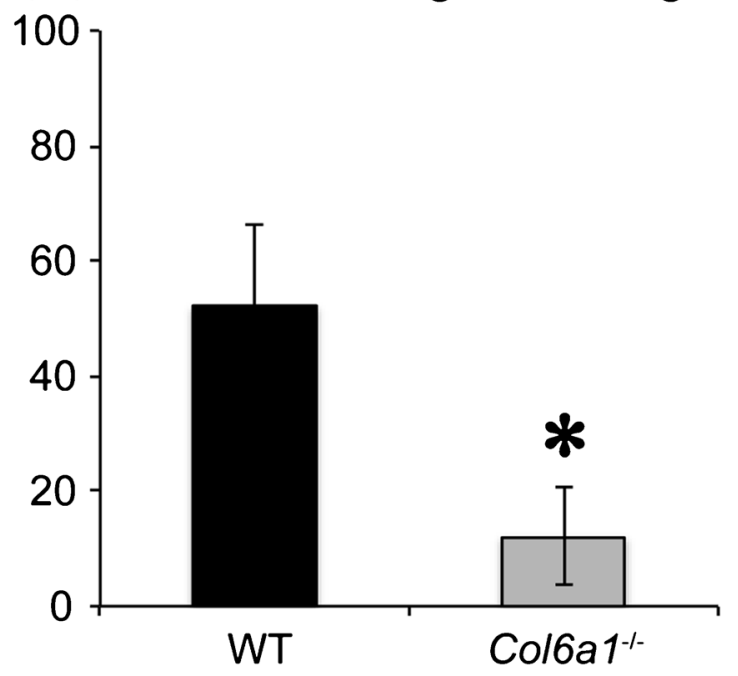

analyses of collagens VI or XII. Statistical analysis revealed that the percentages of cells with collagens VI and XII were significantly higher than those with collagen I. Therefore, the of cells which had bridges positive for both collagens VI and XII. On days 2 and 4, the percentages were $35 \%$ and $53 \%$, respectively, similar to the data obtained for the separate 
matrix bridges formed in adjacent osteoblasts consist of collagens VI and XII.

\section{Complex containing collagens VI and XII is required for matrix bridge formation during osteogenesis}

To elucidate the possible functional relationship between collagens VI and XII, we next investigated whether deficiencies in collagen VI or XII affect matrix bridge formation during osteogenesis. Immunostaining for collagen VI or XII was performed in the primary osteoblasts obtained from wild-type, $\mathrm{Colba1}^{-/-}$, and Col12a1 ${ }^{-/-}$mice after culture under osteogenic conditions (Fig. 6a-1). Matrix bridge formation was absent or decreased in Colba1 ${ }^{-/-}$or Col12al ${ }^{-/}$osteoblasts (Fig. 6a-1). Quantification of cells which had matrix bridges revealed that matrix bridge formation was significantly decreased in primary osteoblasts from Col6a1 ${ }^{-/-}$or Col12al ${ }^{-1-}$ mice compared with that from wild-type mice (Fig. $6 \mathrm{~m}$, n). These data strongly indicate that collagens VI and XII form a complex during matrix bridge formation, and that this complex is required in order to establish communicating cell networks during bone formation.

\section{Discussion}

During bone formation, establishment of well-organized communicating cell networks is essential for appropriate osteoblast maturation and subsequent bone matrix secretion, which collectively define bone volume and quality. Here, we demonstrate, for the first time, the existence of a novel coordinated regulatory mechanism involving collagens VI and XII. This regulates the formation of communicating osteoblast networks that control/promote bone formation. Matrix bridge formation is specific for collagens VI and XII, and the regulation of this process requires the presence of both collagens. Our data indicate that the interaction between collagens VI and XII regulates cell-cell interactions at bone-forming sites during bone formation.

At bone-forming sites, well-arranged osteoblasts interact through gap junctions, tight junctions, and the receptorligand system. Impaired cell-cell interactions result in defects in bone mass (Chaible et al. 2011; Lecanda et al. 2000; Watkins et al. 2011); therefore, cell-cell interactions are essential for the formation of healthy, strong bones. Our present data indicate that collagens VI and XII colocalize, and that this colocalization is restricted to matrix bridges between adjacent osteoblasts during the establishment of communicating cell networks. Interestingly, we also found that collagens XII and I colocalize; however, the localization pattern of these collagens is distinct from that observed for collagens VI and XII. Thus, the function of the collagen VI and XII complex is as a specific regulator, facilitating communicating cell
Fig. 6 Collagen VI or XII deficiency disrupts matrix bridge formation. Primary osteoblasts obtained from wild-type $(W T)$, Col6a1 $1^{-/-}$, or $\mathrm{Coll}_{2 \mathrm{al}^{-/-}}$mice were cultured in osteogenic medium for 4 days and were then immunostained for collagen VI (a-f) and XII (g-l) with DiI (red) and DAPI (blue). Collagen VI (green) bridge formation (arrows) between adjacent cells was detected in osteoblasts from WT mice $(\mathbf{a}, \mathbf{b})$. In contrast, most collagen VI was accumulated on the cell surface, and a few fine bridges (double arrows) were detected in Col1 $2 \mathrm{al}^{-/}$osteoblasts $(\mathbf{e}, \mathbf{f})$. Similar to collagen VI staining in Col12al ${ }^{-/}$osteoblasts, collagen XII (green) expression was limited in Col6al ${ }^{-/}$osteoblasts (asterisks in i, j). Note the collagen XII matrix bridge (arrow) g, h. Bars $50 \mu \mathrm{m}$ Quantification of collagen bridges $(\mathbf{m}, \mathbf{n})$. The percentage of cells harboring collagen bridges was calculated based on immunostaining on day 4. Collagen VI bridge formation was significantly decreased in Col12al ${ }^{-/}$osteoblasts compared with WT osteoblasts (m). Similarly, collagen XII bridge formation was significantly decreased in Col6al ${ }^{-/}$ osteoblasts (n). $* P<0.02$

network formation that is required at the beginning of bone formation.

In addition to the colocalization of collagens VI and XII, we also demonstrate that deficiencies in collagen VI or XII impair matrix bridge formation, suggesting that matrix bridge formation requires both collagens VI and XII. This is the first evidence demonstrating a functional interaction between collagens VI and XII. In support of the current data, our previous reports demonstrate that deficiencies in collagen VI (Izu et al. 2012) and collagen XII (Izu et al. 2011b) result in a disorganized osteoblast arrangement at bone-forming sites and therefore cause decreased bone mass and fragility. We have also demonstrated that collagen XII regulates cell-cell communications via gap junctions in osteoblasts. These observations strongly indicate that the collagen VI/XII complex regulates the sequence of events necessary for the formation of communicating cell networks. Therefore, these interactions are critical in establishing well-organized osteoblasts at bone-forming sites.

The structure of collagen matrix bridges, as determined in this study, might be similar to that of cell protrusions or cell bridges (Zhang and Zhang 2013). Our immunolocalization analysis has occasionally demonstrated collagen VI and XII localization on the tips of cell protrusions. However, most collagen VI and XII bridges seem to connect cell bodies rather than cell protrusions. In addition, immunostaining without the use of permeabilization together with Dil labeling or phase contrast images has revealed the distinct extracellular localization of collagens VI and XII. In the typical process of fibril formation with collagen I, procollagens are released into the extracellular environment through secretory vacuoles known as Golgi-to-plasma membrane carriers (GPCs). Although the details of the GPC secretion pathway are still under investigation, fibril formation is known to occur in compartments associated with both cell protrusions and cell bodies, and no clear evidence has demonstrated that protrusion formation is required for collagen secretion (Banos et al. 2008; Birk and Trelstad. 1986; Kalson et al. 2015). Further studies should investigate the mechanisms involved in matrix bridge formation. 
Extracellular collagens $\mathrm{VI}$ and XII

Extracellular collagens I and XII
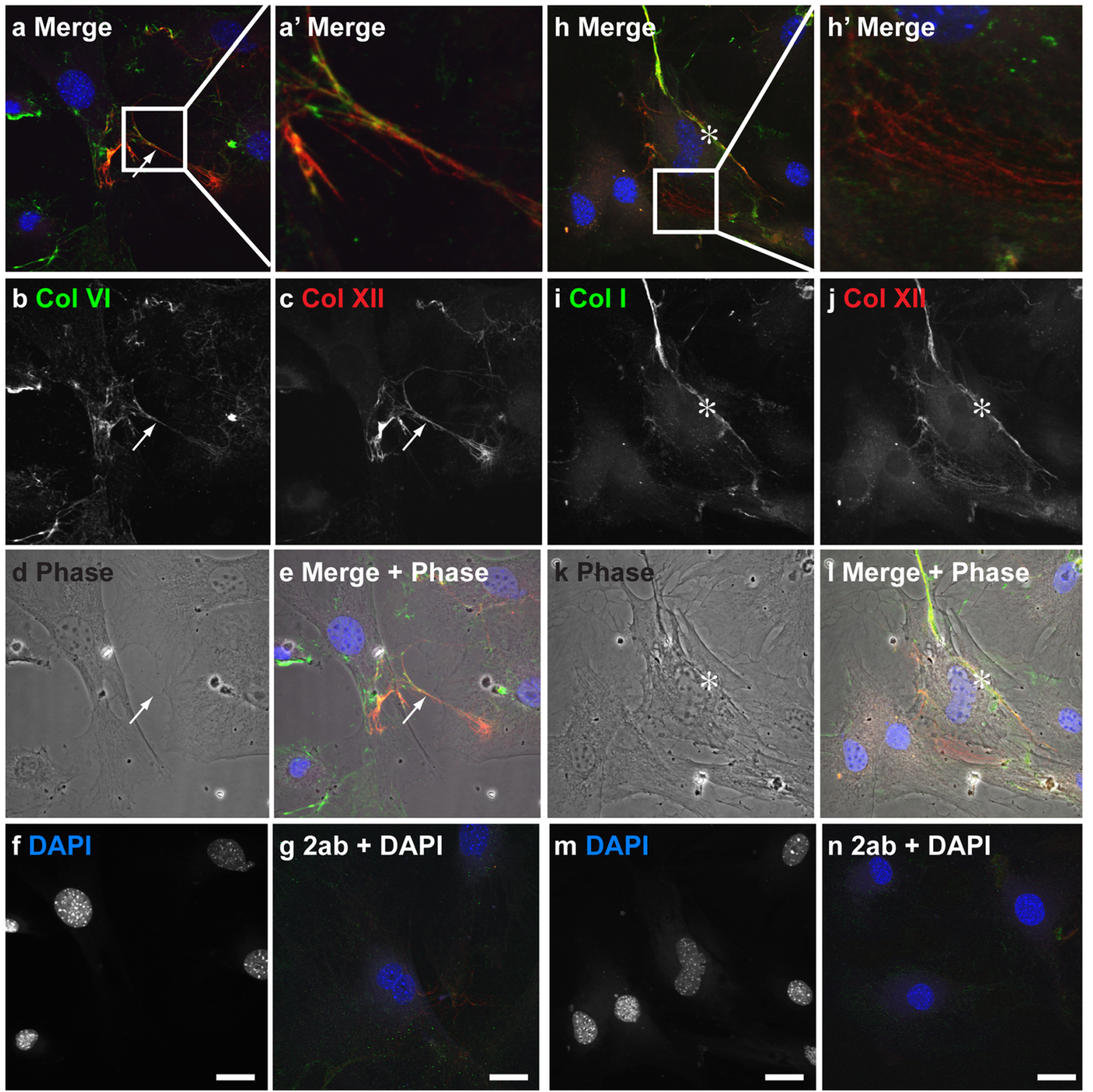

n 2ab + DAPI

- Percentage of the cells with collagen bridges

(\%)

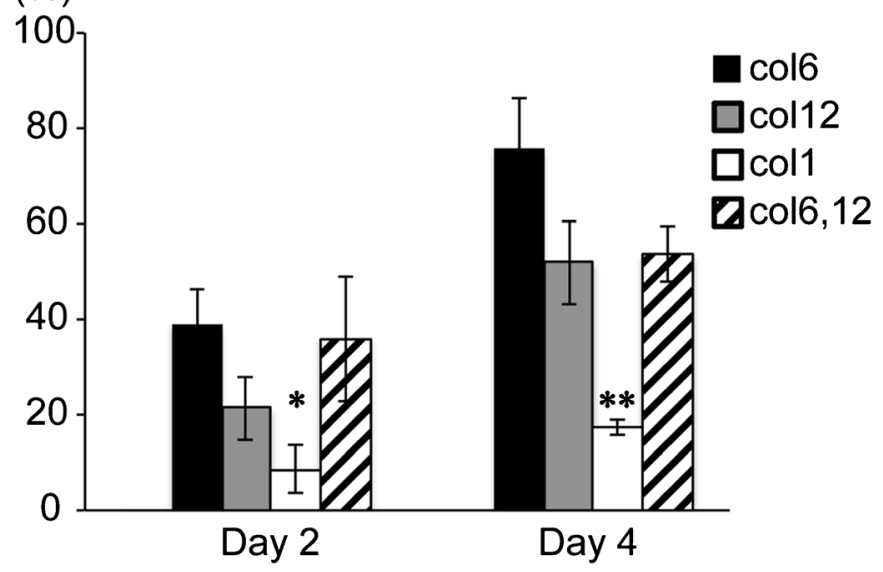


In this study, we have found that collagen VI deficiency decreases collagen XII deposition in our culture system and vice versa. These data are inconsistent with a previous report in which no abnormalities in collagen VI immunoreactivity have been observed in fibroblasts obtained from patients with COL12A1 mutations (Hicks et al. 2014), and the same is true for the COL6 mutation cases. This can be explained by differences in the culture period, because we analyzed the cells as cell-cell connections are beginning to form, whereas skin fibroblasts in the previous study were analyzed at confluence (Hicks et al. 2014). Alternatively, this difference might be explained by differences in cell type (Jimenez-Mallebrera et al. 2006). Although the data are different to some degree, both studies support the idea that a deficiency in at least one type of collagen is sufficient to cause BM and UCMD. Therefore, the coordinated role(s) of collagens VI and XII in a single mechanism are indispensable for the function of the complex, and each collagen cannot compensate for the dysfunction of the other.

The comparison between non-osteogenic and osteogenic medium has revealed that the extracellular localization of collagen VI is independent of the osteogenic medium, whereas the extracellular collagens I and XII are restricted under osteogenic conditions. This is consistent with our western blot analysis of culture medium, suggesting that collagen VI is secreted prior to collagen I and XII by osteoblasts during very early stages. However, collagen VI assembly might not be sensitive to ascorbate, which is generally required for collagen triple helix formation, since no ascorbate was supplemented in the non-osteogenic medium. In contrast, triple helixes of collagens I and XII might not be stable and could be retained intracellularly without ascorbate (Franceschi and Iyer 1992).

Alternatively, the secretion of collagens I and XII might be closely associated. Collagen XII belongs to the FACIT subfamily and is associated with collagen I fibril assembly. In addition, our data have demonstrated the pericellular colocalization of collagens I and XII during osteogenesis. Many studies have shown that Collal mRNA is not expressed during very early stages of osteogenesis but is present during the middle phases of osteoblast differentiation under osteogenic conditions (Askmyr et al. 2009; Hu et al. 2005), suggesting that the extracellular secretion of collagen XII is dependent on collagen I secretion. Therefore, collagen VI might be secreted earlier than collagen XII, and these two collagens might function together when collagen XII is secreted by osteoblasts during bone formation.

Although mutations in collagens VI or XII cause BM and UCMD, the functional contributions of collagen VI and XII in these diseases are still controversial (Allamand et al. 2011; Bernardi and Bonaldo. 2008; Grumati et al. 2010; Hicks et al. 2014; Lamande et al. 2002; Zou et al. 2014). Dysfunction of mitochondria and impaired clearance by autophagy has been shown to induce spontaneous apoptosis, leading to the development of BM and UCMD (Bonaldo et al. 1998; Grumati et al. 2010; Irwin et al. 2003). Because the disruption of cell-cell connections induces apoptosis (Kalvelyte et al. 2003; Wilson et al. 2000), our data indicate that the impaired formation of communicating cell networks between myocytes and muscular fibroblasts and tenocytes, skin fibroblasts, and osteoblasts might be the key to developing BM and UCMD.

In conclusion, we demonstrate, for the first time, that a functional interaction occurs between collagens VI and XII in primary osteoblasts during osteogenesis. Although collagens VI and XII are different subtypes of collagen, both collagens are indispensable for function in establishing communicating cell networks at bone-forming sites, as required for appropriate bone formation.

Open Access This article is distributed under the terms of the Creative Commons Attribution 4.0 International License (http:// creativecommons.org/licenses/by/4.0/), which permits unrestricted use, distribution, and reproduction in any medium, provided you give appropriate credit to the original author(s) and the source, provide a link to the Creative Commons license, and indicate if changes were made.

\section{References}

Allamand V, Brinas L, Richard P, Stojkovic T, Quijano-Roy S, Bonne G (2011) ColVI myopathies: where do we stand, where do we go? Skelet Muscle 1:30

Anderson S, SundarRaj S, Fite D, Wessel H, SundarRaj N (2000) Developmentally regulated appearance of spliced variants of type XII collagen in the cornea. Invest Ophthalmol Vis Sci 41:55-63

Askmyr M, Sims NA, Martin TJ, Purton LE (2009) What is the true nature of the osteoblastic hematopoietic stem cell niche? Trends Endocrinol Metab 20:303-309

Baldock C, Sherratt MJ, Shuttleworth CA, Kielty CM (2003) The supramolecular organization of collagen VI microfibrils. J Mol Biol 330: 297-307

Ball S, Bella J, Kielty C, Shuttleworth A (2003) Structural basis of type VI collagen dimer formation. J Biol Chem 278:15326-15332

Banos CC, Thomas AH, Kuo CK (2008) Collagen fibrillogenesis in tendon development: current models and regulation of fibril assembly. Birth Defects Res C Embryo Today 84:228-244

Bernardi P, Bonaldo P (2008) Dysfunction of mitochondria and sarcoplasmic reticulum in the pathogenesis of collagen VI muscular dystrophies. Ann N Y Acad Sci 1147:303-311

Birk DE, Trelstad RL (1986) Extracellular compartments in tendon morphogenesis: collagen fibril, bundle, and macroaggregate formation. J Cell Biol 103:231-240

Bonaldo P, Braghetta P, Zanetti M, Piccolo S, Volpin D, Bressan GM (1998) Collagen VI deficiency induces early onset myopathy in the mouse: an animal model for Bethlem myopathy. Hum Mol Genet 7:2135-2140

Chaible LM, Sanches DS, Cogliati B, Mennecier G, Dagli ML (2011) Delayed osteoblastic differentiation and bone development in Cx43 knockout mice. Toxicol Pathol 39:1046-1055

Chen P, Cescon M, Zuccolotto G, Nobbio L, Colombelli C, Filaferro M, Vitale G, Feltri ML, Bonaldo P (2015) Collagen VI regulates peripheral nerve regeneration by modulating macrophage recruitment and polarization. Acta Neuropathol 129:97-113 
Chiquet M, Birk DE, Bonnemann CG, Koch M (2014) Collagen XII: protecting bone and muscle integrity by organizing collagen fibrils. Int J Biochem Cell Biol 53:51-54

Doane KJ, Howell SJ, Birk DE (1998) Identification and functional characterization of two type VI collagen receptors, alpha 3 beta 1 integrin and NG2, during avian corneal stromal development. Invest Ophthalmol Vis Sci 39:263-275

Dublet B, Oh S, Sugrue SP, Gordon MK, Gerecke DR, Olsen BR, van der Rest M (1989) The structure of avian type XII collagen. Alpha 1 (XII) chains contain 190-kDa non-triple helical amino-terminal domains and form homotrimeric molecules. J Biol Chem 264:13150-13156

Engel J, Furthmayr H, Odermatt E, von der Mark H, Aumailley M, Fleischmajer R, Timpl R (1985) Structure and macromolecular organization of type VI collagen. Ann N Y Acad Sci 460:25-37

Engvall E, Hessle H, Klier G (1986) Molecular assembly, secretion, and matrix deposition of type VI collagen. J Cell Biol 102:703-710

Font B, Eichenberger D, Rosenberg LM, van der Rest M (1996) Characterization of the interactions of type XII collagen with two small proteoglycans from fetal bovine tendon, decorin and fibromodulin. Matrix Biol 15:341-348

Font B, Eichenberger D, Goldschmidt D, Boutillon MM, Hulmes DJ (1998) Structural requirements for fibromodulin binding to collagen and the control of type I collagen fibrillogenesis - critical roles for disulphide bonding and the C-terminal region. Eur J Biochem 254: 580-587

Franceschi RT, Iyer BS (1992) Relationship between collagen synthesis and expression of the osteoblast phenotype in MC3T3-E1 cells. J Bone Miner Res 7:235-246

Gordon MK, Gerecke DR, Olsen BR (1987) Type XII collagen: distinct extracellular matrix component discovered by cDNA cloning. Proc Natl Acad Sci U S A 84:6040-6044

Grumati P, Coletto L, Sabatelli P, Cescon M, Angelin A, Bertaggia E, Blaauw B, Urciuolo A, Tiepolo T, Merlini L, Maraldi NM, Bernardi P, Sandri M, Bonaldo P (2010) Autophagy is defective in collagen VI muscular dystrophies, and its reactivation rescues myofiber degeneration. Nat Med 16:1313-1320

Hemmavanh C, Koch M, Birk DE, Espana EM (2013) Abnormal corneal endothelial maturation in collagen XII and XIV null mice. Invest Ophthalmol Vis Sci 54:3297-3308

Hicks D, Farsani GT, Laval S, Collins J, Sarkozy A, Martoni E, Shah A, Zou Y, Koch M, Bonnemann CG, Roberts M, Lochmuller H, Bushby K, Straub V (2014) Mutations in the collagen XII gene define a new form of extracellular matrix-related myopathy. Hum Mol Genet 23:2353-2363

Howell SJ, Doane KJ (1998) Type VI collagen increases cell survival and prevents anti-beta 1 integrin-mediated apoptosis. Exp Cell Res 241: 230-241

Hu H, Hilton MJ, Tu X, Yu K, Ornitz DM, Long F (2005) Sequential roles of Hedgehog and Wnt signaling in osteoblast development. Development 132:49-60

Irwin WA, Bergamin N, Sabatelli P, Reggiani C, Megighian A, Merlini L, Braghetta P, Columbaro M, Volpin D, Bressan GM, Bernardi P, Bonaldo P (2003) Mitochondrial dysfunction and apoptosis in myopathic mice with collagen VI deficiency. Nat Genet 35:367-371

Izu Y, Mizoguchi F, Kawamata A, Hayata T, Nakamoto T, Nakashima K, Inagami T, Ezura Y, Noda M (2009) Angiotensin II type 2 receptor blockade increases bone mass. J Biol Chem 284:4857-4864

Izu Y, Ansorge HL, Zhang G, Soslowsky LJ, Bonaldo P, Chu ML, Birk DE (2011a) Dysfunctional tendon collagen fibrillogenesis in collagen VI null mice. Matrix Biol 30:53-61

Izu Y, Sun M, Zwolanek D, Veit G, Williams V, Cha B, Jepsen KJ, Koch M, Birk DE (2011b) Type XII collagen regulates osteoblast polarity and communication during bone formation. J Cell Biol 193:11151130

Izu Y, Ezura Y, Mizoguchi F, Kawamata A, Nakamoto T, Nakashima K, Hayata T, Hemmi H, Bonaldo P, Noda M (2012) Type VI collagen deficiency induces osteopenia with distortion of osteoblastic cell morphology. Tissue Cell 44:1-6

Jimenez-Mallebrera C, Maioli MA, Kim J, Brown SC, Feng L, Lampe AK, Bushby K, Hicks D, Flanigan KM, Bonnemann C, Sewry CA, Muntoni F (2006) A comparative analysis of collagen VI production in muscle, skin and fibroblasts from 14 Ullrich congenital muscular dystrophy patients with dominant and recessive COL6A mutations. Neuromuscul Disord 16:571-582

Kalson NS, Lu Y, Taylor SH, Starborg T, Holmes DF, Kadler KE (2015) A structure-based extracellular matrix expansion mechanism of fibrous tissue growth. Elife 4:e05958

Kalvelyte A, Imbrasaite A, Bukauskiene A, Verselis VK, Bukauskas FF (2003) Connexins and apoptotic transformation. Biochem Pharmacol 66:1661-1672

Keene DR, Lunstrum GP, Morris NP, Stoddard DW, Burgeson RE (1991) Two type XII-like collagens localize to the surface of banded collagen fibrils. J Cell Biol 113:971-978

Koch M, Bohrmann B, Matthison M, Hagios C, Trueb B, Chiquet M (1995) Large and small splice variants of collagen XII: differential expression and ligand binding. J Cell Biol 130:1005-1014

Lamande SR, Morgelin M, Selan C, Jobsis GJ, Baas F, Bateman JF (2002) Kinked collagen VI tetramers and reduced microfibril formation as a result of Bethlem myopathy and introduced triple helical glycine mutations. J Biol Chem 277:1949-1956

Lecanda F, Warlow PM, Sheikh S, Furlan F, Steinberg TH, Civitelli R (2000) Connexin43 deficiency causes delayed ossification, craniofacial abnormalities, and osteoblast dysfunction. J Cell Biol 151:931-944

Massoudi D, Malecaze F, Soler V, Butterworth J, Erraud A, Fournie P, Koch M, Galiacy SD (2012) NC1 long and NC3 short splice variants of type XII collagen are overexpressed during corneal scarring. Invest Ophthalmol Vis Sci 53:7246-7256

Mienaltowski MJ, Birk DE (2014) Structure, physiology, and biochemistry of collagens. Adv Exp Med Biol 802:5-29

Nishiyama T, McDonough AM, Bruns RR, Burgeson RE (1994) Type XII and XIV collagens mediate interactions between banded collagen fibers in vitro and may modulate extracellular matrix deformability. J Biol Chem 269:28193-28199

Oh SP, Taylor RW, Gerecke DR, Rochelle JM, Seldin MF, Olsen BR (1992) The mouse alpha 1(XII) and human alpha 1(XII)-like collagen genes are localized on mouse chromosome 9 and human chromosome 6. Genomics 14:225-231

Veit G, Hansen U, Keene DR, Bruckner P, Chiquet-Ehrismann R, Chiquet M, Koch M (2006) Collagen XII interacts with avian tenascin-X through its NC3 domain. J Biol Chem 281:27461-27470

Walchli C, Koch M, Chiquet M, Odermatt BF, Trueb B (1994) Tissuespecific expression of the fibril-associated collagens XII and XIV. J Cell Sci 107:669-681

Watkins M, Grimston SK, Norris JY, Guillotin B, Shaw A, Beniash E, Civitelli R (2011) Osteoblast connexin 43 modulates skeletal architecture by regulating both arms of bone remodeling. Mol Biol Cell 22:1240-1251

Watt SL, Lunstrum GP, McDonough AM, Keene DR, Burgeson RE, Morris NP (1992) Characterization of collagen types XII and XIV from fetal bovine cartilage. J Biol Chem 267:20093-20099

Wilson MR, Close TW, Trosko JE (2000) Cell population dynamics (apoptosis, mitosis, and cell-cell communication) during disruption of homeostasis. Exp Cell Res 254:257-268

Zhang J, Zhang Y (2013) Membrane nanotubes: novel communication between distant cells. Sci China Life Sci 56:994-999

Zou Y, Zwolanek D, Izu Y, Gandhy S, Schreiber G, Brockmann K, Devoto M, Tian Z, Hu Y, Veit G, Meier M, Stetefeld J, Hicks D, Straub V, Voermans NC, Birk DE, Barton ER, Koch M, Bonnemann CG (2014) Recessive and dominant mutations in COL12A1 cause a novel EDS/myopathy overlap syndrome in humans and mice. Hum Mol Genet 23:2339-2352 